\title{
Cine, Historia y jóvenes en el Japón Moderno
}

\author{
Cinema, History and young people in Modern Japan
}

Itzel Arely Rodríguez Cancino ${ }^{1}$

\section{Resumen}

En las últimas décadas, el cine ha sido revalorado como uno de los reflectores más interesantes y puntuales de la sociedad contemporánea, pues retrata prácticas que forman parte de un tiempo y contexto determinado. Sociedades como la japonesa ven en la pantalla grande una plataforma para plasmar y constatar los cambios sociales y culturales que ha atravesado este país en las últimas décadas. Revisar la importancia social e histórica que ha tenido el cine para la sociedad nipona, ayuda a descifrar qué tipo de películas representa la realidad social que viven los japoneses, tomando en cuenta la transformación vertiginosa ocurrida después de la Segunda Guerra Mundial.

Palabras clave: Cine, japonés, jóvenes, Historia, modernidad

\section{Abstract}

In recent decades, cinema has been revalued as one of the most interesting and punctual reflectors of contemporary society, as it portrays practices that are part of a given time and context. Societies like the Japanese see on the big screen a platform to capture and verify the social and cultural changes that this country has gone through in recent decades. Reviewing the social and historical importance that cinema has had for Japanese society, helps to decipher what kind of films the social reality that the Japanese live through, taking into account the vertiginous transformation that occurred after World War II.

Keywords: Japanese, cinema, young people, History, modernity

Recibido: 06 de noviembre de 2019 Aceptado: 15 de diciembre de 2019 Publicado: 20 de diciembre de 2019

${ }^{1}$ Licenciada en Historia por la Universidad Autónoma de Querétaro (UAQ), Santiago de Querétaro, México. Investigador independiente. Correo electrónico: areit_93@hotmail.com 


\section{Presentación}

El cine japonés parte de una serie de fusiones de técnicas importadas desde el teatro, la literatura y las artes visuales, teniendo una historia de más de 100 años, misma que comprende convenios y tendencias que en ocasiones contradicen el contrato social reconocido. Por ende, el cine en Japón emerge como resultado del cosmopolitismo cultural de sus habitantes, y en parte, es resultado de su insistencia en su propia singularidad.

En 1899, aparece el primer corto cinematográfico japonés, un pequeño documental donde se ve danzando a dos geishas. Sería hasta la entrada del siglo XX cuando el país del Sol Naciente daría sus primeros pasos hacia la industria cinematográfica, simbolizada en sus inicios con la figura de Matsunosuke Onoe, quien se convertiría en la primera estrella nacional, participando en varias películas del género "Jidaigeki". ${ }^{2}$ Tanto Matsunosuke, como el director Makino Shozo, se harían sumamente populares en las primeras décadas.

Durante los decenios de los treinta y cuarenta, el cine japonés tuvo la oportunidad de llegar a Occidente con películas como Las hermanas de Gion (Gion no shimai) y Elegía de Naniwa (Naniwa erejî), ambas de 1936, bajo la dirección de Mizoguchi Kenji, las cuales se proyectarían en Estados Unidos. Por otro lado, en el lapso surgieron grandes iconos de la cinematografía japonesa encabezados por el emblemático Akira Kurosawa, quien en 1943 estrenó su opera prima titulada La leyenda del gran Judo (Sanshiro Sugata), en la que retrata la vida del joven Sanshiro Sugata, quien comienza un viaje con la intención de aprender el arte del Jiu-jitsu. ${ }^{3}$ Kurosawa lideró la industria fílmica los siguientes 40 años, teniendo grandes éxitos como Rashomon (1950), Los siete samuráis (1954), Yojimbo (1960), entre otras películas sobresalientes.

Después de la Segunda Guerra Mundial, la sociedad japonesa se vio enfrentada al nuevo orden y salió airosa en la medida de los ajustes realizados en la etapa de la reconstrucción. A partir de la década de los sesenta, el éxito económico tendió a modificar los esquemas sociales de manera acelerada, cambiando las viejas costumbres de la sociedad tradicional japonesa, estos cambios se vieron reflejados en las nuevas producciones cinematográficas de dicho periodo. En el lapso sobresalieron directores como: Yasujiro Ozu, Hiroshi Inagaki e Ishiro Honda. Éste último se adentraría en un género nuevo con su filme de terror antinuclear, Gojira, estrenado

\footnotetext{
${ }^{2}$ El Jidaigeki es un género del teatro, cine y televisión japonesa, donde se representa la vida cotidiana de Edo (periodo de la historia de Japón que corre de 1603 hasta 1868, considerado la época feudal). Fuente: http://tvtropes.org/pmwiki/pmwiki.php/Main/JidaiGeki. 23 de abril de 2015.

${ }^{3}$ El Jiu-jitsu es un arte marcial japonés clásico o Koryu Budo que abarca una variedad amplia de sistemas de combate modernos basados en la defensa "sin armas". Fuente: http://es. wikipedia.org/wiki/Jiu-jitsu. 23 de abril de 2015.
} 
en 1954 (mejor conocido en Occidente como Godzilla). Dicha película surge durante el periodo de posguerra y expresa y representa parte del miedo colectivo de la sociedad japonesa después de los estragos ocasionados por la detonación de las bombas atómicas en Hiroshima y Nagasaki. La cinta Gojira propiciaría la apertura al cine de ficción japonés, que más tarde se convertiría en un género muy explotado no sólo por el cine, sino por otros medios como la literatura, el manga, el anime y la televisión.

En el lapso de los años ochenta y noventa, las cintas japonesas tomaron un rumbo diferente; el primer decenio fue recordado por el cine del género gánster. Al iniciar la siguiente década, las temáticas cambiaron centrándose, sobre todo, en presentar la cotidianidad de las personas y los problemas sociales de su alrededor. Por su parte, el cine Underground llegaría con gran fuerza en el periodo.

\section{El cine como retrato de la sociedad japonesa}

Durante la segunda mitad del siglo XX, Japón experimenta una serie de cambios desde el ámbito económico, tecnológico, cultural y social. Lo anterior, para sopesar la devastación provocada por la Segunda Guerra Mundial. Más adelante, la sociedad japonesa lograría lo inesperado, una redistribución monetaria cuasi equitativa, elevando los salarios de gran parte de la población. Todos estos movimientos salariales se conseguirían conservando en su gran mayoría su identidad cultural, aunque también se sentiría cierta influencia de Estados Unidos debido a la ocupación de este país sobre el nipón al finalizar la Guerra del Pacífico. Sin duda, estos logros económicos requirieron un esfuerzo agotador de toda la sociedad japonesa; la población activa tuvo que trabajar muchas más horas que sus semejantes estadounidenses y europeos, consumiendo mucho menos y ahorrando e invirtiendo mucho más durante un largo periodo.

Las décadas que siguieron a la derrota de Japón en la guerra se pueden ver como una segunda fase de globalización, en la que los regímenes estandarizados económicos, políticos, tecnológicos y los medios de comunicación, hicieron nuevas incursiones en las estructuras sociales de la vida cotidiana. Durante la intervención de Estados Unidos (1945-1952) se implementaron una serie de reformas con la finalidad de renovar las instituciones al interior de la sociedad japonesa y propiciar de nuevo el despegue. El reparto de tierra y la creación de una nueva Constitución fueron parte del paquete para la mejora. A la larga, las medidas ayudaron al cambio social empujado por un crecimiento económico sostenido. Este nuevo estatus obligaría a que los individuos se familiarizaran y se adaptaran con gran rapidez a los 
cambios procedentes del nuevo orden global capitalista, del que Japón se convertiría en líder.

Con la puesta en marcha de las reformas estructurales, los japoneses transformaron su forma de vida. Para la segunda mitad del siglo XX, Japón era un país industrializado con más de un tercio de su población laborando en fábricas, proporción en detrimento del trabajo empleado en la agricultura. La educación también se vio beneficiada con el crecimiento económico, pues para la década de los setenta, casi el 80 por ciento de los estudiantes de nivel secundaría lograron concluir sus estudios con la intención de ingresar a preparatoria, y posteriormente, terminar una carrera universitaria.

La gran prosperidad de los primeros años de posguerra trajo consigo un cambio importante en la cotidianidad japonesa, las personas se convirtieron en compradores en masa, acción que al mismo tiempo fue una respuesta a la bonanza del país. Para finales de los años setenta, más de la mitad de las familias japonesas contaban con un televisor, donde los programas transmitidos más comunes eran series estadounidenses, dramas japoneses y espectáculos de juegos. Japón reafirmaría su entrada al escenario global después de la celebración de los Juegos Olímpicos de Tokio en 1964. De esta manera, los ojos del mundo se enfocarían en el archipiélago japonés. Al paso, la sociedad japonesa empezaría a tener un interés impaciente por la modernidad, a la usanza estadounidense. En este ínterin de cambios, sobresaldrían la contracultura, la música pop y la evasión social de los individuos de su propia realidad social.

La generación desmesurada de aparatos tecnológicos a partir de los sesenta, ya no con el fin de a hacer la guerra, sino para satisfacer las necesidades de las personas, creó una nuevo tipo de urbanización y socialización. El florecimiento tecnológico que vino después de la década de los setenta, estaría fuertemente ligado a la postura consumista de la sociedad japonesa. En 1980, inició la conquista mundial de las compañías japonesas productoras de semiconductores (es decir videojuegos, faxes, teléfonos, etc.) en el mercado mundial, todo esto gracias a la buena calidad en los productos. (Rubio, 2012, p. 327)

Durante las últimas décadas del siglo $\mathrm{XX}$, los cambios sociales continuaron, los valores sociales dieron un giro dramático, la desilusión social sobre todo, proveniente de los sectores más jóvenes, fue notoria debido a las acciones de los mandatarios, que con el paso de los años, estancaron el crecimiento económico del país.

Otro elemento de tensión sería la política estatal contra los individuos con el fin agilizar la competitividad entre ellos, todo esto dentro de un sistema de productividad que tal parecía ya no estaba dando los resultados esperados. La década 
de los noventa culminaría con el derrumbe del proyecto socio-económico de posguerra de altos estándares de crecimiento, dejando a flote las fallas del Estado japonés. Este lapso es considerado como una época pérdida de la sociedad japonesa, años de recesión económica y reestructuración, donde el "crecimiento, consumo y abundancia”, no funcionaron más.

El colapso económico de la década de los noventa, seguido de una tímida recuperación en los primeros años del nuevo siglo, revelarían elementos de la sociedad japonesa que antes parecían haber estado ocultos debajo de los tatamis de las casas japonesas: alto índice de suicidios, violencia doméstica, corrupción empresarial, profunda crisis de autoridad, aumento insólito de la brecha entre ricos y pobres, y desintegración de las relaciones sociales. (Rubio, 2012, p. 327)

Un nuevo ejemplo del cambio en Japón sería la presencia cada vez mayor de inmigrantes procedentes de Corea del Sur, Irán, países del Sudeste Asiático y del Subcontinente Indio, quienes en ocasiones ingresarían al país de manera ilegal, convirtiendo a la sociedad japonesa en una gran multinacional con diversas expresiones. Antes, durante las primeras décadas de la segunda mitad del siglo XX, el país nipón había recibido una gran influencia de Occidente, la misma que había incidido para sacarlo adelante, pero para finales de los años noventa, la nación del Sol Naciente se había convertido en una gran protagonista del mundo globalizado. Las compañías japonesas realizarían convenios con empresas extranjeras con el fin de crear redes de interacción y nuevas rutas comerciales; no sólo se buscaría la unión con compañías manufactureras, también se orientaría la inversión en la producción de música, cine y televisión; así, nacerían grandes asociaciones como la que hubo entre Sony y CBS, además este boom traería la emisión de la cadena televisiva NHK en Tailandia. ${ }^{4}$ De esta manera, Japón se encontraría conectado al mundo.

Las altas y bajas que viviría la sociedad japonesa serían plasmadas y explicadas de diversas formas, sobre todo, a través de varios medios de comunicación. Los libros, la radio, la televisión y el cine, serían algunos de los vehículos para abrir las ventanas de la realidad social que los japoneses vivían día a día.

En este contexto de cambio, la sociedad como objeto de estudio sería analizada por artistas visuales representados por el manga y el anime. El manga es un estilo de historieta japonesa, donde el diseño del dibujo es diferenciado a la perfección debido a la distorsión del estilo, generando una obra auténtica integrante de su cultura; el anime por su parte es la adaptación a la televisión o al cine del manga. En ambos estilos se han plasmado argumentos de ficción, magia y fantasía como parte de la

\footnotetext{
${ }^{4}$ La NHK es una empresa de comunicaciones japonesa que inició transmisiones en 1925 con el sistema radial. https://www3.nhk.or.jp/nhkworld/es/aboutnhk/. 22 febrero 2016.
} 
sátira y critica que rodea a los problemas del Japón contemporáneo. (Napier,2005, p.10)

El cine desde su llegada al país del Sol Naciente, tuvo una aceptación que impresionante. Los japoneses del siglo XIX llamaron Sashin (copia de realidad) a la fotografía, con lo cual demuestra fehacientemente su apego y su confianza en este medio para reflejar la realidad, es decir, la imagen para ellos muestra de manera real su entorno cotidiano y aspectos de su vida. En la primera época de posguerra, en los años cincuenta, cuando llegaron a Japón las primeras películas en color, los japoneses tradujeron technicolor como tennensyshoku (color natural). Technicolor textualmente significa "color técnico" o "color artificial", así es que la traducción al japonés "color natural”, muestra una inversión en el énfasis del valor. Aunado a lo anterior, Munesuke Mita señala lo siguiente:

eran los días de auge del cine, antes de la difusión de la televisión y en los carteles de la sala podía leerse completamente en colores naturales en letras enormes. Era evidente que en esos días todavía estaba presente la misma mentalidad que hizo traducir fotografía como copia de la realidad. (Mita,1996, p. 621)

La relación entre la identidad japonesa y el cine fue realmente notoria hasta la segunda mitad del siglo XX con la llegada y creación de nueva tecnología referente a los medios de comunicación. El cine contemporáneo propone un discurso popular sobre la identidad, representando una búsqueda extendida de la redención y regeneración de la familia, la estabilidad social y el autodescubrimiento de los individuos. Algunas de las primeras películas contemporáneas del cine japonés, centraban su temática en la actitud social de los individuos y las crisis de identidad de muchas personas en su gran mayoría jóvenes. Otros temas tocados serían los referentes a la historia de Japón. Tal es el caso del cine realizado por el director Kinji Fukusaku, quien sería reconocido por obras como Batallas sin honor ni humanidad de 1973, donde presenta el tema de la Segunda Guerra Mundial a través de pequeños grupos mafiosos creados en la prefectura de Hiroshima durante este periodo.

\section{Los jóvenes vistos a través del cine}

La estructura social del Japón es resultado de la interacción del espacio y entornos en los que los individuos se desenvuelven, las ciudades se convierten en espacios donde se llevan a cabo una serie de interrelaciones por parte de los habitantes con la intención de alcanzar una existencia ilimitada, cada uno con su individualidad, acciones y relaciones absolutas. Los jóvenes se someten a las necesidades que el Estado genera, volviéndose sujetos productivos y socialmente activos. Durante las últimas 
décadas del siglo XX, el joven japonés alcanzó un papel importante en la sociedad, al mismo tiempo, fue constantemente presionado por una sociedad impulsora de un espíritu competitivo, por lo que, este empezó a verse inmiscuido en una presión teniendo como única meta encajar en su entorno social. Esta presión provocó que la juventud buscara una manera de salir de su realidad a través de alternativas no convencionales como el suicido, la creación de grupos sectarios y la búsqueda de espacios recreativos ficticios. Estos fueron en parte algunas de las posibilidades para poder escapar de la abrumadora realidad. En este sentido, el cine se convirtió entonces en un medio de información importante en donde existe la posibilidad de realizar trabajos críticos que revelan la tensa situación de la sociedad japonesa.

A continuación se darán algunos ejemplos de cómo el cine toma la figura del joven como parte de su temática. El primer ejemplo es Batalla real del director Takami Koushun. Dicha cinta estrenada en el 2000 y basada en la novela del mismo nombre publicada en 1999, muestra a un Japón donde la mayor autoridad, el Estado, se vuelve mediador del comportamiento social de los individuos. Aquí, las relaciones sociales y el trabajo colectivo pierden sentido, dándose prioridad a la competitividad individual. La trama sigue a un grupo de jóvenes preparatorianos (entre 15 y 18 años de edad), quienes se ven inmiscuidos en un juego mortal, en el cual son obligados a matarse entre sí. La intención del juego es demostrar la capacidad de los individuos y mandar el mensaje de que sólo el más apto puede vencer a los demás; el juego además forma parte de las estrategias de control social que el Estado utiliza para evitar levantamientos sociales.

La obra original que llegaría a tener gran fama internacional sería creada por el escritor y periodista Takami Koushun, graduado de la Universidad de Osaka en la carrera de literatura. De 1991 a 1996, trabajaría para la compañía de noticias Shikoku Shimbun, informando sobre temas políticos, policiacos y económicos. Sería durante su estancia en este lugar donde nacería la idea de escribir su obra. Al finalizar su trabajo en dicha empresa, Koushun buscaría posicionar su novela a través del Japan Grand Prix Horror Novel, donde sería rechazada debido a su contenido altamente polémico, ya que en ella se criticaba el autoritarismo del Estado en contra de la sociedad japonesa, sobre todo, era notoria la fuerte represión hacia los jóvenes para perfeccionar su sistema meritocrático.

Durante la década de los noventa, el cine japonés se centraría en cuestiones sociales, como el incremento del crimen organizado. El celuloide contaba con una gran gama de temas, pero siempre teniendo como eje central los conflictos sociales. Si realizáramos una cronología de los diferentes géneros cinematográficos japoneses durante el siglo XX, encontraríamos diversas formar de abordar a la sociedad japonesa, esto a través de grandes directores empezando por los emblemáticos Akira 
Kurosawa y Yazujiro Ozu, llegando hasta los años noventa donde se expande la baraja con la figura de Takeshi Kitano, quien se destacaría por ser un gran cineasta del género Yakuza.

En el lapso aludido arriba, el cine japonés tuvo modificaciones y diversificó aún más los temas presentados en la pantalla grande. En 1994 se anunciaría la finalización del cine Yakuza con la propuesta Dono totta Otoko. Este género tomó vuelo a lo largo de la década de los ochenta, sin embargo, una vez acabado el auge de este tipo de cine, se dio paso a cintas con tintes más crudos y complejos.

Por lo anterior, surge el cine Underground, cuyo objetivo fue generar una fuerte crítica a las estructuras de poder del Estado japonés. Uno de los ejemplos más emblemáticos lo encarnó Batalla real. Al respecto, Timothy Iles señala que el cine contemporáneo japonés y las nuevas expresiones audiovisuales en la televisión nacional, son una estampa de la sociedad a nivel de identidad y sus transformaciones, sobre todo, las películas proyectadas en los últimos tiempos. Para este autor, los principales ejemplos recaen en las animaciones, tal es el caso de Shinseiki ebangelion de Anno Hideaki, que es una serie de televisión que representa perfectamente la búsqueda de exploración de la sociedad y el existencialismo de los individuos; además de lo anterior, muestra la naciente tecnofobía bien ejemplificada por los enormes monstruos-máquinas que aparecen en la serie. Otro título comentado por Iles es Hagane no renkinjutsushi (Full Metal Alchemits) de Aikawa Sho, propuesta donde se percibe el autodescubrimiento de los individuos y las relación de los mismos con la familia y la sociedad. Los ejemplos ventilados por Timothy Iles demuestran la penetración y amalgamación de la sociedad con los nuevos medios de información. (Iles, 2008, p. 53)

Al final, el cine tiene el don de suavizar ciertos temas, pero en el caso de la juventud, sucede lo contrario y se convierte en una ventana para dejar salir las críticas más duras a la sociedad. La información cinematográfica es familiar a los jóvenes, es parte de su cultura y sus prácticas sociales. En el caso de Japón se magnífica esta intervención al ser una nación con un cruce de tecnología de la información sobresaliente. Sus jóvenes sensibilizan y procesan todo tipo de información audiovisual. Al mismo tiempo que estos medios de comunicación se convierten en plataformas para reflejar su estado de ánimo social.

\section{Referencias}

Bare Buehrer. Beverley. Japanese Films. A Filmography and Commentary, 1921-1989. North Carolina, McFarland, 1990. 
Castells, Manuel. La Era de la Información. Economía Sociedad y Cultura: La Sociedad Red. Vol. I. México, Siglo Veintiuno Editores, 2006.

Ferro, Marc. ¿A quién le pertenecen las imágenes? México, Revista "Istor”, publicación trimestral, N²0, 2005,

Giddens, Anthony. La constitución de la sociedad. Bases para la teoría de la estructuración. Buenos Aires, Amorrortu Editores, 2006.

Gordon, Andrew. A Modern History of Japan. From Tokugawa Times to the Present. Nueva York, Oxford University Press, 2009.

G. Henshall, Kenneth. A history of Japan. From Stone Age to Superpower. New York St., Martin's Press, 2001.

Iles, Timothy. The Crisis of Identity in Contemporary Japanese Film. Personal, Cultural, Nacional. Boston, Brill, 2008.

Jacoby, Alexander. A critical Handbook of japanese film directors. New York, Stone Bridge Press, 2013.

Michiko Tanaka, et al. JAPÓN: Su Tierra e Historia. México, El Colegio de México, 1991.

Morris Suzuki, Tessa. Cultura, Etnicidad y Globalización. La experiencia japonesa, México, Siglo Veintiuno Editores-Universidad Autónoma de México, 1998.

Mita, Munesuke. Psicología social del Japón moderno. México, El Colegio de México, 1996.

Eisenstein, Sergio M. El Sentido del Cine. Buenos Aires, Siglo Veintiuno Editores, 1974.

Nakamura, Takafusa. El Desarrollo económico del Japón Moderno. Madrid, Ministerio de Relaciones Exteriores, Japón, 1985.

Napier, Susan J. Anime. From Akira to Howl's Moving Castle. Experiencing Contemporary Japanese Animation. New York, PALGRAVE Macmillan, 2005.

Onaha, Cecilia. Educación y Democracia. Evolución de la política educativa en el Japón moderno. México, El Colegio de México, 1998.

Pecori, Franco. Cine, Forma y método. Barcelona, Editorial Gustavo Gili, 1977. 
Reguillo Rosana, et. al. Los jóvenes en México. México, Fondo de Cultura Económica, 2013.

Richie, Donald. A hundred years of Japanese film. Concise History, with a Selective Guide to DVDs and Videos. Nueva York, KODANSHA USA, 2012.

Rosenstone, Robert. A. La historia en imágenes/La historia en palabras: reflexiones sobre la posibilidad real de llevar la historia a la pantalla. México, Revista "Istor", Publicación trimestral $\mathrm{N}^{\circ} 20,2005$.

Rubio, Carlos. El Japón de Murakami. Las señas de la identidad del autor de Tokio Blues. Un viaje hacia el país que configura su universo. México, Santillana, 2013.

Schilling, Mark. Contemporary Japanese Film. Boston, Weatherhill, 1999.

Sorlin, Pierre. Sociología del Cine. La apertura para la historia de mañana. México, Fondo de Cultura Económica, 1985.

Sugimoto, Yoshio. Modern Japanese Culture. Port Melbourne, Cambridge, University Press, 2011.

Sugimoto, Yoshio. An Introducing to Japanese Society. Port Melbourne, Cambridge, University Press, 2014.

Warshaw, Steven, et al. Japan Emerges. A concise History of Japan from its Origin to the Present. California, DIABLO PRESS, 1993. 